\title{
STATE-OF-THE-ART
}

\section{Trauma-informed care in the newborn intensive care unit: promoting safety, security and connectedness}

\author{
MR Sanders ${ }^{1,2}$ and SL Hall ${ }^{3}$
}

\begin{abstract}
Both babies and their parents may experience a stay in the newborn intensive care unit (NICU) as a traumatic or a 'toxic stress,' which can lead to dysregulation of the hypothalamic-pituitary-adrenal axis and ultimately to poorly controlled cortisol secretion. Toxic stresses in childhood or adverse childhood experiences (ACEs) are strongly linked to poor health outcomes across the lifespan and trauma-informed care is an approach to caregiving based on the recognition of this relationship. Practitioners of traumainformed care seek to understand clients' or patients' behaviors in light of previous traumas they have experienced, including ACEs. Practitioners also provide supportive care that enhances the client's or patient's feelings of safety and security, to prevent their re-traumatization in a current situation that may potentially overwhelm their coping skills. This review will apply the principles of trauma-informed care, within the framework of the Polyvagal Theory as described by Porges, to care for the NICU baby, the baby's family and their professional caregivers, emphasizing the importance of social connectedness among all. The Polyvagal Theory explains how one's unconscious awareness of safety, danger or life threat (neuroception) is linked through the autonomic nervous system to their behavioral responses. A phylogenetic hierarchy of behaviors evolved over time, leveraging the mammalian ventral or 'smart' vagal nucleus into a repertoire of responses promoting mother-baby co-regulation and the sense of safety and security that supports health and well-being for both members of the dyad. Fostering social connectedness that is mutual and reciprocal among parents, their baby and the NICU staff creates a critical buffer to mitigate stress and improve outcomes of both baby and parents. Using techniques of trauma-informed care, as explained by the Polyvagal Theory, with both babies and their parents in the NICU setting will help to cement a secure relationship between the parent-infant dyad, redirecting the developmental trajectory toward long-term health and well-being of the baby and all family members.
\end{abstract}

Journal of Perinatology (2018) 38, 3-10; doi:10.1038/jp.2017.124; published online 17 August 2017

\section{INTRODUCTION}

Toxic stress, as defined in the eco-bio-developmental framework of Shonkoff et al., ${ }^{1}$ causes frequent, strong or extended activation of a person's stress response system in the absence of buffering relationships. This level of stress, in contrast to positive or tolerable stress, which are of shorter duration, lower intensity and held in check through buffering by strong support systems, can lead to dysregulation of multiple body systems. ${ }^{1,2}$ These include the hypothalamic-pituitary-adrenal (HPA) axis and the immune, endocrine, circulatory and endocrine systems as well. ${ }^{3}$ Developmental and biological disruptions early in life, such as those caused by toxic stresses, impact later health, development and well-being of affected individuals. The groundbreaking research by Felliti et al. ${ }^{4}$ labeled these disruptions as adverse events of childhood (adverse childhood experiences, ACEs). The authors identified 10 such toxic-stress-inducing events, including physical, emotional or sexual abuse, or parental divorce and concluded that a child's experience of multiple ACEs is a major determinant of both his physical and emotional health, and well-being as an adult. Felliti et al. ${ }^{4}$ further hypothesized that this relationship was mediated by the HPA axis. ${ }^{4,5}$

The body responds to stresses in a highly regulated fashion through both central and peripheral components of the parasympathetic and sympathetic branches of the autonomic nervous system and through the neuroendocrine HPA axis. Cortisol, the effector molecule of the HPA axis, is critical to acute activation of the stress response ('fight or flight') by stimulating release of catecholamines and through maintenance of bodily regulatory functions. ${ }^{6}$

Activation of mother's and/or baby's HPA axis as a result of stresses experienced during a woman's pregnancy or an infant's stay in the newborn intensive care unit (NICU) can all adversely impact the infant's neurodevelopment. Indeed, Bergman ${ }^{7}$ suggested that 'the mere absence of the parent creates toxic stress' in the standard NICU and Shah et al. ${ }^{8}$ proposed that any pediatric hospitalization can precipitate toxic stress in the child as well as in the child's parent(s), particularly if the child and family lack support to buffer their experiences. Furthermore, the National Children's Traumatic Stress Network recently designated trauma during a childhood medical illness as an ACE. ${ }^{9}$

Trauma-informed care, first implemented on a large scale by the Substance Abuse and Mental Health Services Administration, endorses the belief that the multiple dimensions of trauma, including physical/bodily and psychological injuries, can have lasting adverse effects on well-being and function. ${ }^{10}$ Several key concepts of trauma-informed care are as follows: (1) realizing the impact that trauma has on people, and that reactions to a past

\footnotetext{
${ }^{1}$ Division of Neonatology, Department of Pediatrics/Neonatology, Connecticut Children's Medical Center, Hartford, CT, USA; ${ }^{2}$ Department of Pediatrics, The University of Connecticut School of Medicine, Farmington, CT, USA and ${ }^{3}$ St. John's Regional Medical Center, Oxnard, CA, USA. Correspondence: Dr MR Sanders, Division of Neonatology, Department of Pediatrics/Neonatology, Connecticut Children's Medical Center, 282 Washington Street, Hartford, CT 06106, USA.

E-mail: msander@connecticutchildrens.org

Received 11 January 2017; revised 30 May 2017; accepted 26 June 2017; published online 17 August 2017
} 
trauma may inform the person's current response to a potentially traumatic situation; (2) recognizing the signs and symptoms of trauma in people and the staff caring for them; and (3) resisting retraumatization, to prevent a situation that represents a tolerable stress from evolving into a toxic stress. ${ }^{10}$

This review will apply the principles of trauma-informed care, within the framework of the Polyvagal Theory as described by Porges, ${ }^{11}$ to care for the NICU baby, the baby's family and their professional caregivers, emphasizing the importance of social connectedness among all. It is our hope that utilizing techniques of trauma-informed care in the NICU setting will help to support the parent-infant dyad in cementing a secure relationship, redirecting the developmental trajectory toward long-term health and well-being of the baby and all family members.

\section{STRESSES IN PREGNANT WOMEN}

The stresses a mother experiences during pregnancy may affect both her baby's behavior and also the structure of the baby's brain. Term infants of mothers who had elevated cortisol levels during early pregnancy had lower scores on the Bayley Scales of Infant Development at 12 months of age. ${ }^{12}$ Full-term infants of mothers with elevated levels during the latter part of pregnancy had larger cortisol responses to heel sticks. ${ }^{13}$ Infants in this cohort, who were born to mothers who reported stress, anxiety and depression during pregnancy, were slower to recover from painful heel sticks, illustrating that the maternal stress response, leading to elevated maternal cortisol levels, can influence the developing fetus and its behavioral response to stress after birth. ${ }^{13}$ Maternal anxiety during pregnancy was found to decrease infants' gray matter density at 6 to 9 years of age. ${ }^{14}$

A pregnant woman's history of ACEs is strongly related to spontaneous preterm birth, ${ }^{15}$ as well as to lower birthweight and lower gestational age of her infant. ${ }^{16}$ Prior struggles with infertility and/or pregnancy loss, maternal medical illness, including chronic health conditions or mental health concerns, lack of support systems, homelessness or intimate partner violence are high-risk factors that may lead to toxic stress in some mothers. ${ }^{17}$ Mothers with high-risk pregnancies may be further stressed by repeated medical visits and procedures, prolonged bedrest or hospitalization leading to separation from other children, and worries over finances or job security. ${ }^{18}$ Typical stresses during labor and delivery, including multiple vaginal exams, and pain and discomfort, can be experienced as traumatic by some women. ${ }^{19}$ Unexpected situations, such as receiving a diagnosis of preeclampsia or being subject to an emergency cesarean section or instrumented delivery, may leave some women feeling as if their bodies failed them and their fetus, and may lead to posttraumatic stress disorder. ${ }^{20}$

\section{STRESSES IN NICU INFANTS}

Each year, over 500,000 newborns are hospitalized in a US NICU. ${ }^{21}$ No matter how brief their stay, separation from mother at birth and through the subsequent hospitalization disrupts the evolutionary biological expectancies of social engagement critical for co-regulation and healthy development of both the baby and parents. Co-regulation occurs in a mutual, synchronous and reciprocal dyadic relationship whose members regulate each other's physiology and behavior. ${ }^{22}$ Early attuned co-regulatory caregiving is the foundation upon which more long-term relationships leading to bonding and attachment are built. Unfortunately in a NICU hospitalization, the co-regulatory parent is at least briefly replaced by equipment to achieve extra-uterine stability for the baby.

Potentially toxic stressors for hospitalized preterm or otherwise ill infants include long periods of separation from their parents, ${ }^{23}$ inconsistent caregivers, repeated painful procedures without environmental supports ${ }^{24-26}$ and a sensory environment that overwhelms the immature brain. ${ }^{27}$ Although preterm infants may initially have exaggerated responses to acute stress, their autonomic and neuroendocrine responses may become blunted as stresses increase, ultimately leading to hyporesponsivity when faced with chronic stress. ${ }^{28}$ Similar to the way that early life experiences of the fetus may alter their brain structure, preterm infants' experiences of pain can lead to a decrease in their white and gray matter maturation at term-corrected age. ${ }^{29}$

Given the impact of early experiences on brain development, the importance of moderating infants' stress in the NICU is recognized. Als et al. ${ }^{27}$ demonstrated that preterm babies who participated in the Newborn Individualized Developmental Care and Assessment Program had improved electroencephalogram coherence and more mature frontal brain structural development by magnetic resonance imaging at term-corrected age, as well as improved neurobehavioral outcomes at 2 weeks and 9 months corrected age. Infants who participated in Welch's Family Nurture Intervention showed increased frontal brain electroencephalogram activity during sleep, potentially indicative of better neurobehavioral outcomes. ${ }^{30}$

Basic research in rodent models demonstrated that rat pups exposed to lower levels of positive maternal behavior, defined as licking and grooming of pups, developed an increased fear of novelty. ${ }^{31}$ Their responses to stress were altered through epigenetic mechanisms mediated by the HPA axis through the glucocorticoid receptor protein. ${ }^{32}$ The impact of epigenetic modifications that occur in infants in response to maternal behavior and/or environmental stress may also affect thyroid and serotonin signaling. The combined effect of altered glucocorticoid, thyroid and serotonin signaling may impact the infant's ability to manage stress all the way into adulthood ${ }^{32}$ and may also be heritable across generations. ${ }^{33-35}$ This compelling evidence of the impact of the early environment through physiologic, structural and epigenetic modifications to the immature brain suggests that the stresses encountered in newborn intensive care alter the developmental template. Concerns for short- and long-term outcomes call for innovative strategies to support optimal medical and developmental care of the preterm or otherwise ill infant during the NICU experience.

\section{MODIFICATION OF THE STRESS RESPONSE THROUGH SOCIAL CONNECTEDNESS}

Although nearly all parents experience some emotional distress related to their infant's NICU hospitalization, risk factors for development of toxic levels of parental stress include a history of ACEs and/or a current experience of other life stressors and disruptions as described. A parent's resilience and buffering support, provided by friends and family or healthcare staff, can diminish their development of toxic stress. ${ }^{36}$

Tolerable levels of stress increase to toxic levels in the absence of buffering relationships and, when chronic, disrupt the mammalian biological imperative of connectedness. ${ }^{37}$ For the NICU baby, the primary relationships to buffer the baby's response to stress should be with the parents. However, parents may be overwhelmed by their own experiences in the NICU and may not sufficiently emotionally engage with their babies to provide the necessary buffering. NICU hospitalization is recognized as potentially traumatic to the parents and family-in addition to the infant. $^{38}$

Some parents may become upset by watching their baby experience painful and invasive procedures, witnessing cardiopulmonary resuscitation, processing and interpreting alienating medical jargon, and feeling a lack of control and/or helplessness, when they feel their role as parents is not recognized and respected. 39,40 They may also be torn between the emotions of hope and fear. NICU parents are at higher risk for both postpartum 
depression, acute stress disorder, and post-traumatic stress disorder than parents of healthy term babies. ${ }^{41,42}$ The smaller and sicker the preterm baby is, the higher the parents' risk. ${ }^{41}$

As the infant's emotional and behavioral development can suffer in the absence of early social connections, ${ }^{43}$ a key component of family-centered developmental care is to promote sustained parental engagement. Seminal work by Bowlby ${ }^{44}$ recognized the critical importance of the mother/infant bond as a secure base for the infant to develop and explore the world as essential to any infant's normal development. In the NICU dyad, strong parent-infant connections can enhance both short- and long-term developmental outcomes of vulnerable newborns. Guidelines of the National Perinatal Association, ${ }^{45}$ Coughlin et al., ${ }^{46}$ Montirosso et $a .^{47}$ and Flacking et al. ${ }^{23}$ all emphasize the importance of both physical and emotional closeness of parents and their babies to improve outcomes for NICU infants. The Family Nurture Intervention described by Welch et al. ${ }^{48}$ involved simple measures to establish a calming cycle routine between mothers and their preterm infants, resulting in significant improvements in the preterm infants' neurodevelopment, social relatedness and attention assessed at 18 months' corrected age.

\section{THE POLYVAGAL THEORY IN THE NICU}

Porges, ${ }^{11}$ the originator of the Polyvagal Theory, describes social connectedness as 'the ability to mutually (synchronously, symbiotically, and reciprocally) regulate physiological and behavioral state.' Social connectedness built upon the platform of autonomic co-regulation is guided by the unconscious felt sense or 'neuroception' of safety, danger or life-threat. The ability to engage in social connectedness is a result of the evolution of the autonomic nervous system, particularly the tenth cranial or vagus nerve, and the migration of the vagal nerve nucleus from a reptilian dorsal location forward to its ventral mammalian location in the nucleus ambiguus. ${ }^{11}$

Early vertebrates, ancient reptiles, had a dorsally placed vagal nucleus and their behavioral options when a predator was sensed were limited to feigning death, blending in or freezing. Without a functioning sympathetic nervous system, reptiles depend upon the dorsal or 'vegetative' vagal nucleus for protection to slow metabolism, conserve energy, shut down and blend into the environment. As vertebrates evolved eventually into mammals, the vagal nerve nucleus moved from a dorsal to ventral position in the brainstem and the sympathetic nervous system developed, expanding the behavioral hierarchy to allow for the 'fight or flight' response in the presence of predators.

Finally, the social communication system emerged in mammals, with their prolonged period of dependency on a caregiver, leveraging the now ventral or 'smart' vagal nucleus in the nucleus ambiguus. Integration of the myelinated vagus is responsible for the neural control of the heart and of the special visceral efferent pathways regulating the striated muscles of the face, head and neck. This face-heart connection is the neural platform linking social behavior and autonomic regulation that manifests in facial expression, eye contact and vocal prosody to blunt the potentially adverse effects of the HPA axis as it responds to stress. ${ }^{11}$

Movement through this hierarchy is guided by the 'neuroception' of safety, danger or life threat. In the NICU, this neuroceptive or felt sense is seen daily in the faces and behaviors of parents, families, NICU staff and babies. When mother and her baby are engaged in skin-to-skin care-perhaps the best example of coregulation between mother and baby in the NICU settingmother's autonomic expression of safety is reflected in her soft facial features and soothing voice, while her sleeping baby's autonomic stability is evidenced by reassuring levels of oxygenation, heart rate and respirations. Only in mammals can facial expression, eye contact and vocal prosody bring the infant and her caregiver into the mutual, reciprocal and synchronous regulation of physiology and behavior that signals safety and connectedness. ${ }^{11}$ The release of maternal oxytocin such as during breastfeeding also blunts the release of stress hormones and enhances parental caregiving. ${ }^{49}$

As the infant resting in skin-to-skin care is returned to the incubator, her heart rate accelerates and she begins to flail signifying her displeasure at the interruption of her safe and secure nest in skin-to-skin. As her sympathetic nervous system is activated with a fight or flight response, her monitor portrays her autonomic arousal and dysregulation with tachycardia, diminished oxygen saturation and irregular respirations. The cost of her sympathetic arousal is high, as cortisol and catecholamines surge, leaving the baby metabolically depleted. Finally, if the arousal is not appreciated and addressed, the baby may eventually collapse in a dorsal vagal-mediated state of immobilization and surrender. This collapse is often misinterpreted as the baby 'tolerating' the procedure, but it is more likely that the baby's sympathetic nervous system is exhausted, leaving the baby in an energyconserving, vegetative mode, mediated by the dorsally placed reptilian vagal nucleus.

Porges et al. ${ }^{50}$ studied the maturation of vagal tone in term and preterm newborns through the measurement of ECG recordings of heart rate to determine respiratory sinus arrhythmia, an index of neural control of the heart. A higher respiratory sinus arrhythmia is associated with improved vagal tone and more autonomic response flexibility to both internal and external stressors. ${ }^{50}$ It is a non-invasive indicator of the baby's underlying ability to selfregulate, through vagal nerve mediation, key behavioral and physiologic functions, including feeding and digestion. Respiratory sinus arrhythmia typically increases with gestational age. ${ }^{51}$ It is also predictive of behavioral, cognitive and motor outcomes of very low birth weight infants at 3 years of age. ${ }^{52}$

Feldman and Eidelman ${ }^{53}$ studied two cohorts of very low birthweight infants in the NICU. The experimental group experimental group received skin-to-skin, also known as Kangaroo Care, for $1 \mathrm{~h}$ daily for 14 days, whereas the control group received standard incubator care. Infants who received skin-to-skin had more rapid maturation of vagal tone between 32 and 37 weeks' gestational age and improved state organization. ${ }^{53}$ The authors followed these cohorts and found that the skin-to-skin group had increased respiratory sinus arrhythmia, correlating with higher vagal tone and improved autonomic functioning, at 10 years of age. $^{54}$

Changes in an infant's vagal tone in response to parental interaction in the NICU can be seen in her level of autonomic reactivity, as illustrated in Journalist Kelley Benham French's recounting of the NICU hospitalization of her former 23 weeks' gestation baby, Juniper. The impact of the environment on Juniper's autonomic reactivity influenced by changes in her mother's voice is seen in the following anecdote described by Ms. French.

When you read to her, she can tell you, by the numbers and waves on her monitor, not to use the scary voice for the paragraphs about Voldemort. She can tell you which songs she wants you to sing. She can tell you, emphatically, to play 'Waitin' On A Sunny Day' one more time.

Understanding the safety-seeking behaviors of parents and babies through the Polyvagal Theory lens helps providers utilize appropriate trauma-informed interventions including respectful, nonjudgmental personalized care, stemming from a partnership with the parent. Providers who are well self-regulated can use their own social connectedness to co-regulate the parent who may be oscillating between sympathetic overdrive and dorsal vagal collapse. For example, the frightened parent of a critically ill infant who first sobs, while in a state of sympathetic overdrive, and 
Table 1. SAMHSA's six key principles of a trauma-informed approach ${ }^{10}$ adapted for a NICU setting

\begin{tabular}{|c|c|}
\hline Principle & Application in the $\mathrm{NICU}^{a}$ \\
\hline 1.Safety (physical and psychological) for parents and staff & $\begin{array}{l}\text { - Privacy is afforded (best done in single family rooms). } \\
\text { - Confidentiality is maintained. } \\
\text { - Mutual respect is demonstrated. } \\
\text { - Providers are caring, empathic, and validate parents' experiences. }\end{array}$ \\
\hline 2.Trustworthiness and transparency & $\begin{array}{l}\text { - Communication, free of medical jargon, is frequent and regular. } \\
\text { - Parents' concerns and questions are respected. } \\
\text { - Parents have access to their baby's medical records. } \\
\text { - Parents' presence on rounds and during shift change is encouraged. }\end{array}$ \\
\hline 3.Peer support & $\begin{array}{l}\text { - Every NICU should offer peer support to every NICU parent within } 72 \mathrm{~h} \text { of admission. } \\
\text { - Peer support can be provided one-on-one, in a group setting, by telephone or } \\
\text { internet. }\end{array}$ \\
\hline 4.Collaboration and mutuality & $\begin{array}{l}\text { - Parents are partners with the NICU team. } \\
\text { - Nurses take the role of mentor and coach to parents. } \\
\text { - Parents are involved in the care of their baby as early and as often as possible. } \\
\text { - Family-integrated care is a promising new model. } \\
\text { - Shared decision-making for baby's care plans is standard. } \\
\text { - Nurse-physician collaboration is practiced. }\end{array}$ \\
\hline 5.Empowerment, voice and choice for parents and staff & $\begin{array}{l}\text { - Parents are provided emotional and psychosocial support to foster their resilience. } \\
\text { - Parents are encouraged and supported in taking on their roles as parents and } \\
\text { caregivers. } \\
\text { - Parents' presence on rounds and during shift change is encouraged. } \\
\text { - Staff are supported with appropriate assignments, mentoring, and self scheduling. }\end{array}$ \\
\hline 6.Cultural, historical and gender issues & $\begin{array}{l}\text { - All parents are welcomed and treated equally. } \\
\text { - Culturally effective care is provided to all. }\end{array}$ \\
\hline
\end{tabular}

Abbreviations: NICU, newborn intensive care unit; SAMHSA, Substance Abuse and Mental Health Services Administration. ${ }^{\text {a }}$ The applications were derived from the 'Interdisciplinary Recommendations for Psychosocial Support of NICU Parents'60 and from 'Trauma-Informed Care in the NICU.'62

then 'clams up' and collapses into a dorsal vagal state while seeing another critically ill infant admitted in the next bedside can be reassured that her emotions are understandable. The medical and nursing teams can emphasize their own physical and emotional availability by sitting quietly with this mother who is potentially retraumatized by the admission of the new baby. Using a soothing voice and prosody, the health care provider can support the parent's self-regulation into more emotional availability and willingness to talk. Parents need reassurance that the medical team will keep them and their baby safe. However, assurances should be carefully and cautiously stated, recognizing the uncertain prognoses accompanying the many infant diagnoses in the NICU.

Everyone benefits when physicians recognize that their own relationships with babies and their families require 'the person-toperson attunement that is essential for the development of the newborn., 56

As French again comments:

Our doctors and nurses didn't just treat our baby. They loved her. They made us feel safe enough that we could love her, too. ${ }^{55}$

Through the Polyvagal Theory lens, the 'difficult parent or family' is now understood as one whose neuroception of danger plays out in either sympathetic arousal or in dorsal vagal collapse. The sympathetically-aroused family may appear angry, explosive, challenging, overwhelming, irritable or tense, while the family who senses life-threatening danger may seem emotionless, uncaring, hard to reach or unavailable. The previously immobilized and withdrawn family who explodes in anger is actually moving toward a window of tolerance that will open the door to improved communication and understanding. ${ }^{57}$ With an understanding of Polyvagal Theory, NICU staff are also able to shift from wondering about parents, 'What is wrong with them?' to a trauma-informed reflection of 'What happened to them?'
For example, a mother of an extremely preterm baby who was hostile, suspicious and challenging of both the nursing and medical staff had numerous ACEs in her history (childhood abuse, parental divorce and alcoholism). In addition, her brother had died in the past year and the father of her baby was murdered during her pregnancy. To this mother, the NICU represented danger and potential loss of another loved one; her response was to aggressively try to protect her baby from harm. With the recognition of 'what happened to this mother,' the NICU assigned primary care nurses and one primary neonatologist to communicate with her. In her newfound safety, the mother was cautiously and slowly able to forge supportive connections and move forward to collaboratively partnering with the NICU team around her baby's care.

\section{ADAPTATION OF PRINCIPLES OF TRAUMA-INFORMED CARE TO THE NICU SETTING}

As pregnancy and the hospital experience can cause toxic stresses either by themselves or by possibly triggering a re-traumatization in any patient or their family members, we endorse a 'universal precautions' approach ${ }^{58}$ when interacting with all perinatal and NICU patients and their families. The Substance Abuse and Mental Health Services Administration developed six key principles of a trauma-informed approach ${ }^{10}$ and we adapted the NICU applications of these principles from two primary sources as shown in Table 1. The first is the 'Interdisciplinary Recommendations for Psychosocial Support of NICU Parents. ${ }^{59}$ The recommendations describe a systematic and multi-dimensional approach to supporting babies and families through the challenges of the NICU in six content areas (peer support, role of mental health professionals, family-centered developmental care, palliative and bereavement care, post-discharge follow-up and staff education and support). They were derived through a literature review and development of expert consensus opinion by a multidisciplinary 
group of professionals and parents convened by the National Perinatal Association. The foundation of the recommendations of the National Perinatal Association is enhancement and leveraging of social engagements between parents and baby, and among parents, baby and staff creating the necessary parental 'psychological space' to promote attunement and co-regulation. ${ }^{60}$

The second source is the foundational body of work by Coughlin et al. ${ }^{39,46,61}$ outlining guidelines and recommendations for care practices for the NICU baby in five areas as follow: (1) protecting sleep, (2) managing pain and stress, (3) developmental activities of daily living, (4) family-centered care and (5) the healing environment. Recommendations by Coughlin et al., $39,46,61$ which fully support parent-caregiver partnerships, overlap considerably with the National Perinatal Association recommendations.

The principles and practices of family-centered developmental care are the foundation of these techniques, mediated through caregiving relationships (with parents and all staff, especially nurses) enhancing the baby's feeling of safety and security. ${ }^{61}$

\section{TRAUMA-INFORMED CARE OF THE FAMILY AND BABY: NEWBORN INTENSIVE PARENTING UNITS}

Given the critical importance of social connectedness, transitioning from the historical provider-focused paradigm of care of the NICU to newborn intensive parenting units is necessary to ensure that the biological imperative of parent-baby connectedness can be further supported, as parents are recognized and promoted as the primary co-regulators of their babies. ${ }^{62}$ Developmental care of the baby by parents and staff enhances baby's adaptation, resilience and tolerance of stress. ${ }^{63,64}$ Parents' stresses may lessen, too, as their perceptions of their baby's discomfort diminish.

Skin-to-skin or Kangaroo Care is an evidence-based best practice of trauma-informed care to promote parent-infant connection, lessen stress of both members of the dyad, and enhance parental confidence. ${ }^{62-65}$ In their landmark study, Feldman and Eidelman ${ }^{53}$ showed that skin-to-skin care improves autonomic function, attenuates stress, improves maternal attachment behavior, reduces maternal anxiety and enhances child cognitive developmental outcomes from 6 months to 10 years of age. Additional studies of skin-to-skin care show lower maternal depression and improved maternal confidence, as well as lower infant salivary cortisol, accelerated functional brain maturity and improved cognitive and communication performance of infants at 6 and 12 months of age. ${ }^{63-66}$

Parents should be central in the prevention, assessment and management of babies' pain and stress. They should be included in decisions on pharmacologic and non-pharmacologic comfort measures for their baby on a daily basis, as well as before, during and after procedures. Parent-driven non-pharmacologic measures can include breastfeeding, skin-to-skin care both at rest and during procedures, multisensory stimulation, facilitated tucking, positioning, swaddling and non-nutritive sucking. ${ }^{67,68}$ In the absence of family, nurses can also provide non-pharmacologic measures including oral sucrose. ${ }^{69}$ Parents can also assist staff in identifying techniques that most benefit their babies. Pharmacologic measures including the provision of narcotics, and benzodiazepines, may also be cautiously implemented as needed with family input.

Other interventions to promote parent-infant connection include mothers seeing their baby within $3 \mathrm{~h}$ of delivery ${ }^{70}$ and participating actively in their baby's NICU care, ${ }^{71}$ especially in the family-integrated care model, where parents take on primary caregiving responsibilities for their babies, performing many tasks previously done by the nursing staff. The family-integrated care model pilot showed better infant weight gain, increased breastfeeding at discharge and increased maternal confidence in the babies cared for in the integrated-care model compared with controls. ${ }^{72,73}$ It is now being replicated at 20 NICUs throughout Canada, Australia and New Zealand.

The development of single family room (SFR) NICUs is an environmental intervention that can increase parent-baby social engagement and connectedness. Recent studies showed infants in SFRs gained weight better, reached full feeds earlier, had less sepsis, required fewer medical procedures and showed less pain and stress than infants cared for in an open-bay NICU. ${ }^{74}$ Furthermore, infants cared for in SFRs with high levels of maternal involvement had improved neurodevelopmental outcomes at 18 months compared with infants cared for in an open bay NICU with similarly high levels of maternal involvement. ${ }^{75}$ The mediating effect of maternal involvement is key to addressing concerns raised by Pineda et al. ${ }^{76}$ regarding delayed language development for infants cared for in SFRs.

Social circumstances in the United States may interfere with mothers spending prolonged time in the hospital caring for their babies. These include mothers' needs to return to the workplace while their baby is still hospitalized, a lack of adequate affordable and safe childcare for siblings, and disparities in public transportation. To respond to these challenges will require flexible care environments in NICUs moving forward, as SFRs may be too socially and developmentally isolating for babies whose families are unable to be present. These babies may benefit from care in group rooms where their development and interaction with both NICU staff and parents can be promoted, but families should still have the availability of private rooms when they are able to be present with their baby. ${ }^{77}$ Nurses also reported less stress and less emotional exhaustion working in SFRs. ${ }^{75}$

However, before one concludes that any parent cannot be available more continuously to their baby, staff should look at the family's engagement with their baby and the providers through a Polyvagal Theory lens. Staff may wish to examine their own attitudes toward the family and their presence in the hospital. What neuroceptive sense of safety or danger do they feel in the family's presence? How does the family signal their own neuroception of the hospital environment? Obtaining the assistance of medical social workers or mental health professionals may shed light on the reason for the family's absence, offer opportunities for engaging or mending gaps in communication and help identify concrete supports that may assist a family. ${ }^{78}$

\section{PROACTIVE COMMUNICATION AND EDUCATIONAL STRATEGIES}

Techniques to minimize a parent's emotional distress during a NICU hospitalization include providing personalized care in partnership with the parent, rather than in a hierarchical relationship. Fenwick et al. ${ }^{79}$ described the importance of neonatal nurses 'chatting' or engaging in social talk, at the bedside with the mothers of babies in their care. Expressing care, support and interest in mothers through exchanging personal stories is a way that nurses can engage them, boost their confidence and their connection to their infants. Although 'chatting' minimizes the hierarchical differences that exist in the traditional medical model of providing care, it is important to recognize staffs' professional and personal boundaries.

Explaining all procedures before they take place and keeping communication lines open will help relieve parents' uncertainty and critically ensure their feeling of safety. Recognizing, encouraging, considering parents as experts regarding their own baby, and empowering parents to affirm their primary caregiving parental role will increase their own competence and confidence. Curricula that assist parents in recognizing and interpreting their baby's behavior lead to more sensitive and responsive parentbaby interactions, benefitting both. ${ }^{80,81}$ Additional traumafocused interventions include psychoeducation, guided muscle relaxation and rewriting one's trauma narrative. A program with 
these components, developed by Shaw et al., ${ }^{82}$ reduced symptoms of trauma and depression in mothers of preterm infants. In addition, veteran NICU parents can provide peer support to current NICU parents as a way to expand their social system. ${ }^{83}$

\section{PROVIDING TRAUMA-INFORMED SUPPORTS TO STAFF CARING FOR PREGNANT WOMEN, NEW MOTHERS, FAMILIES AND BABIES}

Physicians, nurses and other staff working in Labor and Delivery, or in the NICU, may suffer vicarious traumatization and are prone to burnout, compassion fatigue, secondary traumatic stress syndrome and posttraumatic stress disorder. ${ }^{84-89}$ Staff resilience scores are inversely correlated with posttraumatic stress disorder symptoms and emotional exhaustion. ${ }^{90}$

Self-regulation of staff is critical to their ability to assist families in their own self-regulation. When staff and parents regulate themselves, their social connectedness with each other and with the baby is reinforced, benefitting the baby, who is dependent upon the sensitivity of caregivers to provide co-regulation for her. All staff caring for babies and their families can benefit from developing a 'culture of awareness' as described by Steinberg and Kramer $^{91}$ which encourages reflective consideration of 'inner experience and thinking about- rather than acting upon- thoughts and feelings.' Recognizing the importance of creating an environment of caring and compassion for staff as well as families, trained mental health professionals, usually clinical psychologists, are increasingly present in the NICU. ${ }^{78}$ Psychologists and other mental health professionals may serve a critical interpretive role, bridging the space between disappointed, depressed or distraught families, and their medical and nursing providers. ${ }^{92}$ Mental health professionals may use individual family or staff work, multidisciplinary meetings, critical debriefings and in the moment facilitation of communication as portals to improving staff wellbeing and relationships. ${ }^{91-94}$ Just as we seek to understand 'what happened to' families, the system benefits when the NICU culture works to comprehend, integrate and feel compassion for 'what happened to' staff members. Support can also be provided by reflective supervisors and chaplains. ${ }^{95}$

In addition, timely peer psychological support is taught in an on-line module for Psychological First Aid developed through a partnership between the University of Minnesota Preparedness and Emergency Response Learning Center and the Minnesota Department of Health Office of Emergency Preparedness. This approach is appropriate for first responders in the field and hospital personnel dealing with a medical crisis. The free module outlines principles of trauma-informed care and common behavioral, cognitive, and sensory responses of children and adults. The course also outlines four principles of polyvagally informed psychological first aid as follows: (1) promote safety; (2) promote calm and comfort; (3) promote connectedness; and (4) promote self-empowerment. $^{96}$

\section{SUMMARY/CONCLUSIONS}

Understanding the Polyvagal Theory and the mammalian biological imperative for social connectedness guides traumainformed care in the NICU by highlighting the neuroception of safety when the autonomic nervous system is well-regulated. When parents, babies and staff are socially engaged and optimally leveraging the ventral or smart vagus, stresses are diminished. Environmental, sensory and procedural stresses can be minimized, although never eliminated in today's modern intensive care environment. However, stress-buffering through strong social supports and connections can mitigate the short- and long-term impacts, making stressors at worst, tolerable. Particular attention must be paid to those parents whose ACEs predispose them, and their babies, to toxic stressors that may be underappreciated by staff. Considering our intensive care units to be newborn intensive parenting units will focus parents and staff upon the primary relationship of parents and their babies. The care of the parentbaby dyad is then ideally supported by a developmentally sensitive caregiving staff and hospital that are placeholders for the eventual return of the baby-parent unit to their community.

\section{CONFLICT OF INTEREST}

The authors declare no conflict of interest.

\section{ACKNOWLEDGEMENTS}

The authors did not receive any financial or grant support.

\section{REFERENCES}

1 Shonkoff J, Garner A, Siegel B, Dobbins M, Earls M, Garner A et al. The lifelong effects of early childhood adversity and toxic stress. Pediatrics 2012; 129(1): e232.

2 Shonkoff J, Boyce W, McEwen B. Neuroscience, molecular biology, and the childhood roots of health disparities: building a new framework for health promotion and disease prevention. JAMA 2009; 301(21): 2252-2259.

3 Johnson S, Riley A, Granger D, Riis J. The science of early life toxic stress for pediatric practice and advocacy. Pediatrics 2013; 131(2): 319-327.

4 Felitti V, Anda R, Nordenberg D, Williamson D, Spitz A, Edwards V et al. Relationship of childhood abuse and household dysfunction to many of the leading causes of death in adults. The Adverse Childhood Experiences (ACE) Study. Am J Prev Med 1998; 14(4): 245-258.

5 Dong M. Insights into causal pathways for ischemic heart disease: Adverse Childhood Experiences study. Circulation 2004; 110(13): 1761-1766.

6 Nicolaides N, Kyratzi E, Lamprokostopoulou A, Chrousos G, Charmandari E. Stress, the stress system and the role of glucocorticoids. Neuroimmunomodulation 2015; 22(1-2): 6-19.

7 Bergman N. Neuroprotective Core Measures 1-7: neuroprotection of skin-to-skin contact. Newborn Infant Nurs Rev 2015; 15(3): 142-146.

8 Shah A, Jerardi K, Auger K, Beck A. Is hospitalization a toxic stress? Pediatrics 2016; 137(5): 1-3.

9 Pynoos R, Steinberg A, Layne C, Liang L, Briggs E, Habib M et al. Modeling constellations of trauma exposure in the National Child Traumatic Stress Network Core Data Set. Psychol Trauma 2014; 6(S1): S9-S17.

10 Substance Abuse and Mental Health Services Administration. SAMHSA's Concept of Trauma and Guidance for a Trauma-Informed Approach. Substance Abuse and Mental Health Services Administration: Rockville, MD, 2014 Report No.: HHS Publication No. (SMA) 14-4884.

11 Porges SW. The Polyvagal Theory: Neurophysiological Foundations of Emotions, Attachment, Communication, Self-Regulation. Norton Series on Interpersonal Neurobiology. W. W. Norton: New York, 2011.

12 Davis $\mathrm{E}$, Sandman $\mathrm{C}$. The timing of prenatal exposure to maternal cortisol and psychosocial stress is associated with human infant cognitive development. Child Dev 2010; 81(1): 131-148.

13 Davis E, Glynn L, Waffarn F, Sandman C. Prenatal maternal stress programs infant stress regulation. J Child Psychol Psychiatry 2011; 52(2): 119-129.

14 Buss C, Poggi Davis E, Muftuler L, Head K, Sandman C. High pregnancy anxiety during mid-gestation is associated with decreased gray matter density in 6-9 year-old children. Psychoneuroendocrinology 2010; 35(1): 141-153.

15 Christiaens I, Hegadoren K, Olson D. Adverse childhood experiences are associated with spontaneous preterm birth: a case-control study. BMC Med 2015; 13: 124.

16 Smith M, Gotman N, Yonkers K. Early childhood adversity and pregnancy outcomes. Matern Child Health J 2016; 20: 790-798.

17 Zager RP. Psychological aspects of high-risk pregnancy. Glob Libr Women Med 2009 (ISSN: 1756-2228).

18 Beck C. Birth trauma: in the eye of the beholder. Nurs Res 2004; 53(1): 28-35.

19 Beck C. Post-traumatic stress disorder due to childbirth: the aftermath. Nurs Res 2004; 53(4): 216-224.

20 Porcel J, Feigal C, Poye L, Postma I, Zeeman G, Olowoyeye A et al. Hypertensive disorders of pregnancy and risk of screening positive for posttraumatic stress disorder: a cross-sectional study. Pregnancy Hypertens 2013; 3(4): 254-260.

21 US Department of Health and Human Services, Health Resources and Services Administration, Maternal and Child Health Bureau, 2013. Available from http:// mchb.hrsa.gov/chusa13/perinatal-health-status-indicators/p/infant-morbidity.html. 
22 Evans $C$, Porter $C$. The emergence of mother-infant co-regulation during the first year: links to infants' developmental status and attachment. Infant Behav Dev 2009; 32: 147-158.

23 Flacking R, Lehtonen L, Thomsen G, Axelin A, Ahlqvist S, Moran V et al. Closeness and separation in neonatal intensive care. Acta Paediatr 2012; 101(10): 1032-1037.

24 Losacco V, Cuttini M, Griesen G, Haumont D, Pallas-Alonso C, Pierrat V et al. Heel blood sampling in European neonatal intensive care units: compliance with pain management guidelines. Arch Dis Child Fetal Neonatal Ed 2 2011; 96(1): F65-F68.

25 Grunau R. Neonatal pain in very preterm infants: long-term effects on brain, neurodevelopment and pain reactivity. Rambam Maimonides Med J 2013; 4(4): e0025.

26 Montirosso R, Casini E, Del Prete A, Zanini R, Bellu R, Borgatti R. NEO-ACQUA Study Group. Neonatal developmental care in infant pain management and internalizing behaviors at 18 months in prematurely born children. Eur J Pain 2016; 20: 1010-1021.

27 Als H, Duffy F, McAnulty G, Rivkin M, Vajapeyam V, Mulkern R et al. Early experience alters brain function and structure. Pediatrics 2004; 113(4): 846-857.

28 Victoria N, Murphy A. The long-term impact of early life pain on adult responses to anxiety and stress: historical perspectives and empirical evidence. Exp Neurol 2016; 275(Part 2): 261-273.

29 Brummelte S, Grunau R, Chau V, Poskitt K, Brant R, Vinall J et al. Procedural pain and brain development in premature newborns. Ann Neurol 2012; 71(3): 385-396.

30 Welch M, Myers M, Grieve P, Isler J, Fifer W, Sahni R et al. Electroencephalographic activity of preterm infants is increased by Family Nurture Intervention: a randomized controlled trial in the NICU. Clin Neurophysiol 2014; 125(4): 675-684.

31 Meaney M, Szyf M, Seckl J. Epigenetic mechanisms of perinatal programming of hypothalamic-pituitary-adrenal function and health. Trends Mol Med 2007; 13(7): 269-277.

32 Champagne F. Early environments, glucocorticoid receptors, and behavioral epigenetics. Behav Neurosci 2013; 127(5): 628-636.

33 Francis D, Diorio J, Liu D, Meaney M. Nongenomic transmission across generations of maternal behavior and stress responses in the rat. Science 1999; 286(5442): 1155-1158.

34 Daxinger L, Whitelaw E. Understanding transgenerational epigenetic inheritance via the gametes in mammals. Nat Rev Genet 2012; 13(3): 153-162.

35 Guerrero-Bosagna C, Skinner M. Environmentally induced epigenetic transgenerational inheritance of phenotype and disease. Mol Cell Endocrinol 2012; 354(1-2): 3-8.

36 Center for the Study of Social Policy. Strengthening Families: a protective factors framework. Available from http://www.cssp.org/reform/strengtheningfamilies/ about\#protective-factors-framework.

37 Porges SW. Connectedness as a Biological Imperative: Understanding Trauma Through the Lens of the Polyvagal Theory. Presented at the New England Society for Trauma and Dissociation: Lexington, Massachusetts, 2014.

38 Janvier A, Lantos J, Aschner J, Barrington K, Batton B, Batton D et al. Stronger and more vulnerable: a balanced view of the impacts of the NICU experience on parents. Pediatrics 2016; 138(3): 1-4.

39 Coughlin M. Transformative Nursing in the NICU: Trauma-Informed Age-Appropriate Care. Springer Publishing Company: New York, 2014; 198.

40 Peebles-Kleiger M. Pediatric and neonatal intensive care hospitalization as traumatic stressor: implications for intervention. Bull Menninger Clin 2000; 64(2): 2257-2280.

41 DeMier R, Hynan M, Harris $H$, Manniello R. Perinatal stressors as predictors of symptoms of posttraumatic stress in mothers of infants at high risk. $J$ Perinatol 1996; 16(4): 276-280.

42 Miles S, Holditch-Davis D, Schwartz T, Scher M. Depressive symptoms in mothers of prematurely born infants. J Dev Behav Pediatr 2007; 28(1): 36-44.

43 Sullivan R, Perry R, Sloan A, Kleinhaus K, Burtchen N. Infant bonding and attachment to the caregiver: insights from basic and clinical science. Clin Perinatol 2011; 38: 643-655.

44 Bowlby J. A Secure Base: Parent Child Attachment and Healthy Human Development. Basic Books: New York, NY, 1988.

45 Craig J, Glick C, Phillips R, Hall S, Smith J, Browne J. Recommendations for involving the family in developmental care of the NICU baby. J Perinatol 2015; 35: S5-S8.

46 Coughlin M, Gibbins S, Hoath S. Core measures for developmentally supportive care in neonatal intensive care units: theory, precedence and practice. $J$ Adv Nurs 2009; 65(10): 2239-2248.

47 Montirosso R, Del Prete A, Bellu R, Tronick E, Borgatti R. Neonatal adequate care for quality of life (NEO-ACQUA) Study Group. Level of NICU quality of developmental care and neurobehavioral performance in very preterm infants. Pediatrics 2012; 129(5): e1129-e1137.

48 Welch M, Firestein M, Austin J, Hane A, Stark R, Hofer M et al. Family Nurture Intervention in the neonatal intensive care unit improves social-relatedness, attention, and neurodeveloment of preterm infants at 18 months in a randomized controlled trial. J Child Psychol Psychiatry 2015; 56(11): 1202-1211.

49 Lee HJ, Macbeth $\mathrm{AH}$, Pagani $\mathrm{JH}$, Young WS 3rd. Oxytocin: the great facilitator of life. Prog Neurobiol 2009; 88(2): 127-151.

50 Porges S, Doussard-Roosevelt J, Maiti A. Vagal tone and the physiological regulation of emotion. Monogr Soc Res Child Dev 1994; 59(2-3): 167-186.

51 Suess P, Alpan G, Dulkerian S, Doussard-Roosevelt J, Porges S, Gewolb I. Respiratory sinus arrhythmia during feeding: a measure of vagal regulation of metabolism, ingestion, and digestion in preterm infants. Dev Med Child Neurol 2000; 42: 169-173.

52 Doussard-Roosevelt J, Porges S, Scanlon J, Alemi B, Scanlon K. Vagal regulation of heart rate in the prediction of developmental outcome for very low birth weight preterm infants. Child Dev 1997; 68(2): 173-186.

53 Feldman R, Eidelman L. Skin-to-skin contact (Kangaroo Care) accelerates autonomic and neurobehavioural maturation in preterm infants. Dev Med Child Neurol 2003; 45(4): 274-281.

54 Feldman R, Rosenthal Z, Eidelman A. Maternal-preterm skin-to-skin contact enhances child physiologic organization and cognitive control across the first 10 years of life. Biol Psychiatry 2014; 75: 56-64.

55 French KB. Things I wish l'd known about having a one-pound baby. Downloaded from https://www.washingtonpost.com/news/parenting/wp/2016/11/17/things-iwish-id-know-about-having-a-one-pound-baby/?utm_term $=.2$ acf440c07f6.

56 Adler HM. The sociophysiology of caring in the doctor-patient relationship. J Gen Intern Med 2002; 17(11): 883-890.

57 Korn D. Treating complex trauma: optimal integration of treatment models. Presented at the Cape Cod Institute, Summer 2016.

58 Zingaro L. Traumatic learning. In: Becoming Trauma-Informed. Center for Addiction and Mental Health: Toronto, Canada, 2013, 29-36.

59 Hall S, Hynan M eds. Interdisciplinary recommendations for the psychosocial support of NICU parents. J Perinatol 2015; 35: S29-S36.

60 Steinberg Z, Patterson C. Giving voice to the psychological in the NICU: a relational model. J Infant Child Adol Psych 2017; 16(1): 25-44.

61 Coughlin M. Trauma-Informed Care in the NICU: Evidence-Based Practice Guidelines for Neonatal Clinicians. Springer Publishing Company: New York, NY, 2017.

62 Hall S, Hynan M, Phillips R, Lassen S, Craig J, Goyer E et al. The neonatal intensive parenting unit (NIPU): an introduction. J Perinatol 2017; e-pub ahead of print 10 August 2017; doi:10.1038/jp.2017.108.

63 Johnson A. The maternal experience of kangaroo holding. J Obstet Gynecol Neonatal Nurs 2007; 36(6): 568-573.

64 Bigelow A, Power J, MacLellan-Peters J, Alex M, McDonald C. Effect of mother/ infant skin-to-skin contact on postpartum depressive symptoms and maternal physiological stress. J Obstet Gynecol Neonatal Nurs 2012; 41(3): 369-382.

65 Boundy E, Dastjerdia R, Spiegelman D, Fawzi W, Missmer S, Lieberman E et al. Kangaroo mother care and neonatal outcomes: a meta-analysis. Pediatrics 2016; 137(1): 1-16.

66 Gonya J, Ray W, Rumpf R, Brock G. Investigating skin-to-skin care patterns with extremely preterm infants in the NICU and their effect on early cognitive and communication performance: a retrospective cohort study. BMJ Open 2017; 7(3): e012985.

67 Campbell-Yeo M, Fernandes A, Johnston C. Procedural pain management for neonates using nonpharmacological strategies: part 2: mother-driven interventions. Adv Neonatal Care 2011; 11(5): 312-318.

68 Liaw J, Yang L, Katherine Wang K, Chen C, Chang Y, Yin T. Non-nutritive sucking and facilitated tucking relieve preterm infant pain during heel-stick procedures: a prospective, randomised controlled crossover trial. Int J Nurs Stud 2013; 50(7): 883-894.

69 Fernandes M, Campbell-Yeo M, Johnston C. Procedural pain management for neonates using nonpharmacological strategies: part 1: sensorial interventions. Adv Neonatal Care 2011; 11(4): 235-241.

70 Mehler K, Wendrich D, Kissgen R, Roth B, Obertheur A, Pillekamp F et al. Mothers seeing their VLBW infants within $3 \mathrm{~h}$ after birth are more likely to establish a secure attachment behavior: evidence of a sensitive period with preterm infants? J Perinatol 2011; 31(6): 404-410.

71 Reynolds L, Duncan M, Smith G. Parental presence and holding in the neonatal intensive care unit and associations with early neurobehavior. J Perinatol 2013; 33 636-641.

72 O’Brien K, Bracht M, Macdonell K, McBride T, Robson K, O'Leary L et al. A pilot cohort analytic study of Family Integrated Care in a Canadian neonatal intensive care unit. BMC Pregnancy Childbirth 2013; 13(Suppl 1): S12.

73 O'Brien K, Bracht M, Robson K, Ye XY, Mirea L, Cruz M et al. Evaluation of the Family Integrated Care model of neonatal intensive care: a cluster randomized controlled trial in Canada and Australia. BMC Pediatr 2015; 15: 210.

74 Lester B, Hawes K, Abar B, Sullivan M, Miller R, Bigsby R et al. Single-family room care and neurobehavioral and medical outcomes in preterm infants. Pediatrics 2014; 134(4): 754-760. 
75 Lester B, Salisbury A, Hawes K, Dansereau L, Bigsby R, Laptook A et al. 18-month follow-up of infants cared for in a single-family room neonatal intensive care unit. J Pediatr 2016; 177: 84-89.

76 Pineda R, Neil J, Dierker D, Smyser C, Wallendorf M, Kidoro H et al. Alterations in brain structure and neurodevelopmental outcome in preterm infants hospitalized in different neonatal intensive care unit environments. J Pediatr 2014; 164(1): 52-60.

77 White R. The next big ideas in NICU design. J Perinatol 2016; 36: 259-262.

78 Hynan M, Steinberg Z, Baker L, Cicco R, Geller P, Lassen S et al. Recommendations for mental health professionals in the NICU. J Perinatol 2015; 35: S14-S18.

79 Fenwick J, Barclay L, Schmied V. "Chatting": an important clinical tool in facilitating mothering in neonatal nurseries. J Adv Nurs 2001; 33(5): 583-593.

80 Feeley N, Zelkowitz P, Westreich R, Dunkley D. The evidence base for the Cues program for mothers of very low birth weight infants: an innovative approach to reduce anxiety and support sensitive interaction. J Perinat Educ 2011; 20(3): 142-153.

81 Milgrom J, Newnham C, Martin P, Anderson P, Doyle L, Hunt R et al. Early communication in preterm infants following intervention in the NICU. Early Hum Dev 2013; 89(9): 755-762.

82 Shaw R, St. John N, Lilo E, Jo B, Benitez W, Stevenson D et al. Prevention of traumatic stress in mothers of preterm infants: a randomized controlled trial. Pediatrics 2013; 132(4): 1-9.

83 Hall S, Ryan D, Beatty J, Grubbs L. Recommendations for peer-to-peer support for NICU parents. J Perinatol 2015; 35: S9-S13.

84 Czaja A, Moss M, Mealer M. Symptoms of post-traumatic stress disorder among pediatric acute care nurses. J Pediatr Nurs 2012; 27(4): 357-365.

85 Weintraub A, Geithner E, Stroustrup A, Waldman E. Compassion fatigue, burnout and compassion satisfaction in neonatologists in the US. J Perinatol 2016; 36: 1021-1026.

86 Profit J, Sharek P, Amspoker A, Kowalkowski M, Nisbet C, Thomas E et al. Burnout in the NICU setting and its relation to safety culture. BMJ Qual Saf 2014; 10: 806-813.

87 Braithwaite M. Nurse burnout and stress in the NICU. Adv Neonatal Care 2008; 8(6): 34-37.
88 Cricco-Lizza R. The need to nurse the nurse: emotional labor in Neonatal Intensive Care. Qual Health Res 2014; 24(5): 615-628.

89 Beck C, Gable R. A mixed methods study of secondary traumatic stress in labor and delivery nurses. J Obstet Gynecol Neonatal Nurs 2012; 41(6): 747-760.

90 Dalia C, Abbas K, Colville G, Brierley J. G49 resilience, post-traumatic stress, burnout and coping in medical staff on the paediatric and neonatal intensive care unit (P/NICU) - a survey. Arch Dis Child 2013; 98: A26-A27.

91 Steinberg Z, Kraemer S. Cultivating a culture of awareness: nurturing reflective practices in the NICU. Zero Three 2010; 31(2): 15-21.

92 Kraemer S. So the cradle won't fall: holding the staff who hold the parents in the NICU. Psychoanal Dial 2006; 16(2): 149-164.

93 Hall S, Cross J, Selix N, Patterson C, Segre L, Chuffo-Siewert R et al. Recommendations for enhancing psychosocial support of NICU parents through staff education and support. J Perinatol 2015; 35: S29-S36.

94 Keene E, Hutton N, Hall B, Rushton C. Bereavement debriefing sessions: an intervention to support health care professionals in managing their grief after the death of a patient. Pediatr Nurs 2010; 36(4): 185-189.

95 Sharp C. Use of the chaplaincy in the Neonatal Intensive Care Unit. South Med J 1991; 84(12): 1482-1486.

96 Minnesota Department of Health. Psychological First Aid (PFA). Downloaded from http://www.health.state.mn.us/oep/responsesystems/pfa.html.

(c) (1)(2) This work is licensed under a Creative Commons Attributioncc) NonCommercial-ShareAlike 4.0 International License. The images or other third party material in this article are included in the article's Creative Commons license, unless indicated otherwise in the credit line; if the material is not included under the Creative Commons license, users will need to obtain permission from the license holder to reproduce the material. To view a copy of this license, visit http:// creativecommons.org/licenses/by-nc-sa/4.0/

(c) The Author(s) 2018 